\title{
Regulation of Indoor Environmental Conditions in Houses: Preference and behaviour studies
}

\author{
Noor Hanita Abdul Majid, Mohd Syafiq Salehuddin, \\ Zaiton Abdul Rahim, Rosniza Othman
}

Department of Architecture, Kulliyyah of Architecture and Environmental Design, International Islamic University Malaysia, Jalan Gombak, P.O.Box 10, 50728 Kuala

Lumpur, Malaysia

hanita@iium.edu.my; muhamadsyafiq@iium.edu.my; zaiton@iium.edu.my; rosniza@iium.edu.my

\begin{abstract}
Regulating the indoor environment for comfort and energy savings requires appropriate attutude and human behaviour of the house inhabitants. The aim of this study is to identify people's main concerns when building or choosing a home. The research intends to determine how human behaviour regulates the indoor environmental conditions in houses towards achieving comfort and energy savings. A questionnaire survey was conducted through random sampling method with approximately 125 respondents. The results indicated the preferences for comfort and inhabitants' attitude and behaviour in regulating the indoor environment.
\end{abstract}

Keywords:human behaviour; comfort; energy savings; house

eISSN 2514-7528 @ 2018. The Authors. Published for AMER ABRA cE-Bs by e-International Publishing House, Ltd., UK. This is an open-access article under the CC BY-NC-ND license (http://creativecommons.org/licenses/bync-nd/4.0/). Peer-review under responsibility of AMER (Association of Malaysian Environment-Behaviour Researchers), ABRA (Association of Behavioural Researchers on Asians) and CE-Bs (Centre for EnvironmentBehaviour Studies), Faculty of Architecture, Planning \& Surveying, Universiti Teknologi MARA, Malaysia.

DOI: https://doi.org/10.21834/jabs.v3i10.313 


\subsection{Introduction}

'Baiti Jannati', 'Rumahku Syurgaku' or 'My home, My heaven' is a concept that has been propagated in Malaysia since 1992 for inhabitants to regard the home as a place of refuge. As a reflection of heaven, a place of refuge, should accommodate the needs of human behaviour and provide comfort. The idea is to achieve comfort with minimal use of energy. The tendency and inclination to rely on air-conditioning effect the energy demand and emissions of $\mathrm{CO}$. The cooling needs and reliance on the air-conditioning has exacerbate rather than mitigate climate change.

Hence, a home should be designed in view of energy efficiency that relies mainly on attitude and behaviour of the inhabitants. It is important to gauge the attitude of house inhabitants in regulating the indoor environment. What are the attitude of the house inhabitants towards energy efficiency. How do they control the indoor environment to achieve comfort? What are the steps taken? What are the preferences of inhabitants in achieving comfort? What affects their choices in achieving thermal comfort? These questions are inevitable to understand how the above concept of Baiti Jannati can be realise and the attitude and behaviour of the house inhabitants. In addition, to achieve comfort and energy savings requires appropriate human behavior; where the inhabitants are integral in regulating the indoor environment.

The aim of this paper is to discuss people's main concerns given the choice of specifying their needs in designing and habituating a home. The objectives of this study are to identify people's main concerns when building or choosing a home. What factors are the main concern; comfort, privacy, aesthetic or flexibility? The research intends to ascertain the awareness of of people on energy savings and energy efficiency. In addition, the research intends to investigate the importance of energy efficiency to homeowners. Understanding the concerns represent the respondents preferences when building or choosing a home. The research intends to determine how the house inhabitants control the indoor environment to achieve comfort. The prefences of the inhabitants by using different means will be recorded. It is hypothesized that the level of education and age of the respondents relate to the awareness and behavioural conduct of homeowners. In addition, the research intends to determine how human behaviour regulates the indoor environmental conditions in houses towards achieving comfort and energy savings.

\subsection{Literature Review}

This research looks into issues of respondents' preferences, attitude and behaviour to achieve comfort in houses.

Human behaviour is the anticipated as the main factor that govern the quest for comfort in the houses. Many researches have been conducted to determine how human behaviour has influenced different sectors of energy savings of both commercial and residential building (Bell et al.,1996; Wilk, 1999; Lutzenhiser, 1993). Ibrahim and Noor Hanita (2014) have forwarded that major issues in households energy use are associated with energy efficiency as: architectural (design) issue, appliances/services (technology) efficiency issue, and the 
human (behavioural) issue. The results of the study indicated that there are strong correlation between attitude and behaviour to energy efficiency in the houses. It is interesting to note that the study found that age and level of education of the respondents are the influncing factors towards the occupants attitude to energy savings. Diez-Nicholas (2006) forwarded that preceding human behaviour is the attitude factor. According to him, attitude preceded behaviour and propagated that it as instrumental collective responses of the population to achieve the best adaptation possible to their environment. Factors such as education/ awareness and social status may have implication on energy efficiency awareness but not necessarily determine it (Abdul Majid and Hussaini, 2011).

Achieving comfort is one of the underlying factors in the regulation of an indoor environment. Vischer (2007) proposed three levels of comfort considerations including physical, functional and psychological. The basic physical comfort factor adopted by Vischer is that a home should provided shelter from physical treat in the environment. This basic definition can be elaborated further if physical comfort is discussed in detail; where physical comfort can relate to thermal, visual and spatial qualities. In achieving energy efficiency, users' perception of the important consideration for the environment will be in terms of lighting and space (Nadzirah et.al, 2012).

Furthermore, comfort can also be through esthetic, visual and thermal comfort, and flexibility in the use of spaces. Aesthetics is seen as another factor considered by homeowners. Masran et. al (2012) discussed how homeowners renovated their house to achieve different aesthetical preferences. The authors suggested that people are expressive towards their aesthetic preferences, although it is interesting to note that $32 \%$ of the case study have opted for modern tropical style.

Sociocultural factors such as privacy also contributed to comfort of the inhabitants. Zaiton and Ahmad Hariza (2012) stated that ideally house designs should meet and support the needs of a family in terms of the activity system, privacy and social interaction. These requirements need to be seen in line and enhanced with the requirements to regulate the indoor environment for comfort purposes too. Different regions have unique architectural solution as a reaction to a given environment. Architecture in each region gives us precious lessons of the perception, behavior and specific solutions to the natural environment which formed the regional specific culture (Hoang, 2013).

All factors discussed laid the criteria for a comfortable house. Nevertheless, the current houses faced problems in achieving desired comfort. Zaiton (2007) studied the modifications made by the inhabitants of two storey low cost housing to meet comfort means due to the need for more space and privacy. She also added that the house inhabitants also have to seek a balance or sacrifice the privacy or thermal factors to achieve comfort. The discussion was also discussed by Noor Hanita et al. (2009) in looking at the responsive strategies versus the cultural and religious dimensions in the architecture of malay traditional houses. The inhabitants chose between having privacy by limiting or closing openings, or thermal comfort by opening the doors and windows to allow for cross ventilation. The matter also has been further discussed by Noor Hanita et al. (2004) to discuss the equalibrium between social and climatic considerations in design new houses. Moreover, Ahmad Ezanee et al. (2012) studied 
factors that influenced the performance of low cost public housing and dissatisfaction among the inhabitants. The researchers found that the residents who live in public housing highlighted their dissatisfaction in terms of natural lighting, air circulation, garbage and noise among other facilities and social conditions.

\subsection{Methodology}

The regulation of comfort can be achieved through inhabitants behavioural actions and choices in the houses. The research is conducted through questionnaire survey to identify how the respondents plan to adapt to a given condition in achieving comfort. A questionnaire survey was conducted through convenient sampling method with approximately 125 respondents. The survey administered consist of demographic data of the respondents and choice of dependent variables on regulation of the indoor environment.

\subsection{Results and Discussions}

The results indicated the respondents' preferences for comfort and awareness on energy savings. These findings are important parameters to be considered in understanding the human behaviour in regulating the indoor environment and designing comfortable houses. Figure 1 shows that the preference for comfort (64\%) and privacy (47\%) are an important considerations to achieve in house design. The concept of comfort in this question is generic where comfort can be described in terms of thermal, visual or audio comfort. The results show that the respondents are more concern on the quality of living and sustainabilty of the houses. The survey results showed that the respondents choose thermal comfort as the most important consideration at $67 \%$, visual comfort (25.6\%) and audio comfort (5.6\%).

As thermal comfort is the most important consideration in choosing a house, regulating the indoor environment by attitude and behaviour is most important (Noor Hanita and Hussaini, 2011 and 2012). The survey results indicated that the respondents chose opening windows $(43.2 \%)$ over switching on fans or air conditioner $(25.6 \%)$. The results suggest awareness of energy efficiency through the choice of maintaining thermal comfort. Moreover, the respondents also rely on passive cooling by opening windows rather than relying on modes using electricity. These passive cooling techniques contributes to energy savings and efficiency in the running cost of the houses. Opening design in the houses should be able to maximise ventilation of the indoor environment that will in turn contribute to thermal comfort. In achieving visual comfort, the respondents regulate daylighting through controlling the window openings $(54.4 \%)$, curtain $(32.8 \%)$ and blinds (12.8\%). The solution for controlling daylight has relied both on the architectural and interior design decisions. Regulating the indoor environment for comfort; thermal or visual comfort suggest the behaviour and attitude of respondents towards energy efficiency in houses. In addition, majority of the respondents also agreed that passive architecture design consideration is important in building design. Incorporation of other energy efficiency and sustainable systems such as rainwater harvesting, greywater treatment and solar panel were voted agreeable by the respondents. 
The respondents agree (59.2\%) to include essential sustainable and energy efficient systems in contemporary houses. Another half of the respondents voted neutral $(36.8 \%)$ and disagree $(2 \%)$ with $3 \%$ missing data. The attitude towards the energy efficiency application in the houses is a 3:2 ratio. This suggests that the awareness towards these system may still be at the initial stage among the respondents. The attitude and behaviour of house inhabitants can be improved upon creation of awareness through education of the young generation.

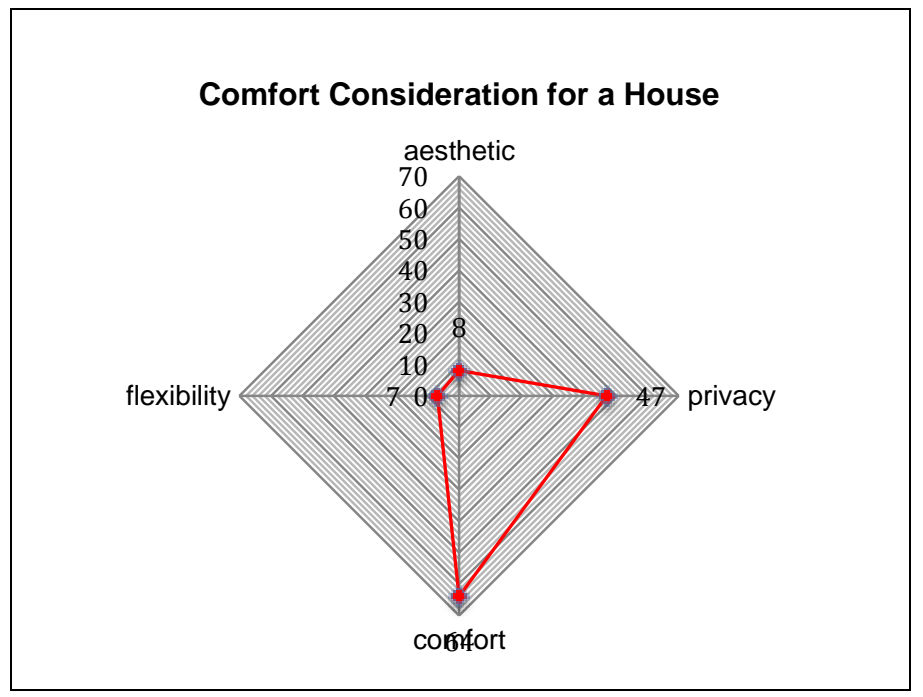

Figure 1: Comfort Consideration for a House

The results of the survey recorded the independent variable of age and education that provided indicators to the awareness and behaviour of the respondents in regulating the indoor environment (Table 1). The percentages of age group for the respondents are $36.8 \%$, $24.5 \%, 24 \%$ and $12.3 \%$ for the four age groups as indicated in figure 2 . The level of education (figure 3$)$ for the respondents are primary $(0.8 \%)$, secondary $(20.8 \%)$, university $(69.2 \%)$ and others $(9.2 \%)$. The higher percentages of, the lower age group or, the younger generation and university educated respondents suggest that a higher level of awareness for the importance of energy efficiency in houses (figure 4). Figure 5 supports the above assumptions where $97.6 \%$ of the respondents voted that the consideration of energy efficiency in designing homes are most important (45.6\%) and important (52\%). These figures asserted that the attitude towards energy savings and efficiency is positive among the respondents. 


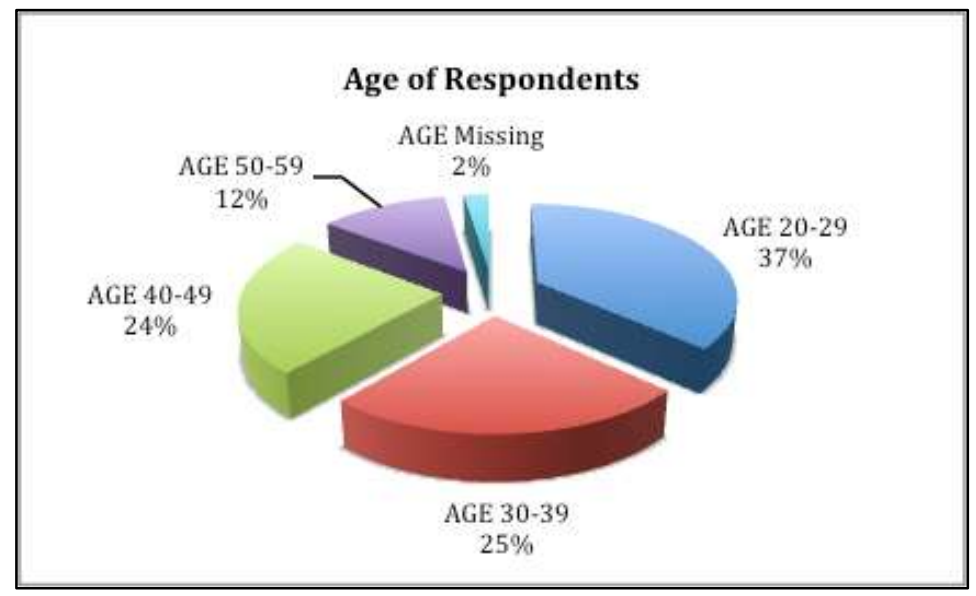

Figure 2: Age of Respondents

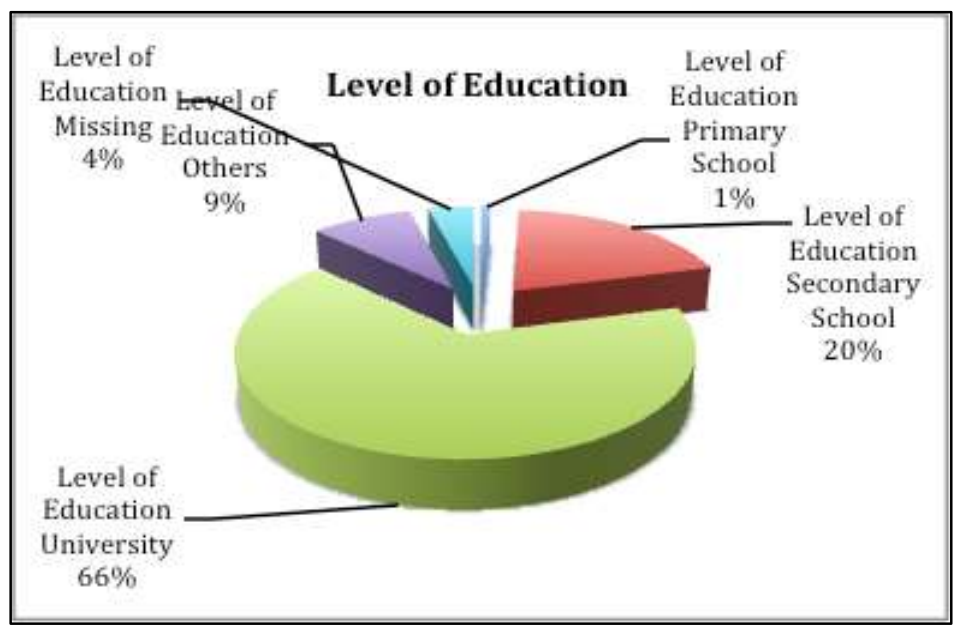

Figure 3: Level of Education 


\section{Awareness of Energy Efficiency}

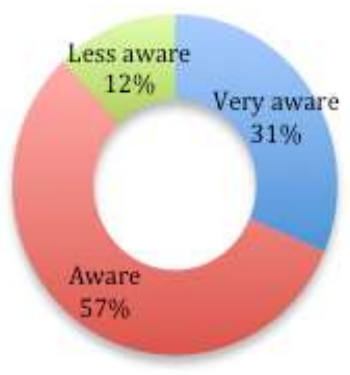

Figure 4: Awareness of Energy Efficiency

\section{Importance of Energy Efficiency}

Figure 5: Importance of Energy Efficiency in Designing Houses 
Table 1: Demographic Variables of the Respondents

\begin{tabular}{lllll}
\hline NO & $\begin{array}{l}\text { DEMOGRAPHIC } \\
\text { VARIABLES }\end{array}$ & DESCRIPTION & FREQUENCY & PERCENTAGES \\
\hline 1 & AGE & $20-29$ & 46 & 36.8 \\
& & $30-39$ & 31 & 24.8 \\
& $40-49$ & 30 & 24 \\
& & 15 & 12.3 \\
2 & Level of Education & Missing & 2.4 \\
& Primary School & 1 & 0.8 \\
& Secondary School & 25 & 20 \\
& University & 83 & 66.4 \\
& Others & 11 & 8.8 \\
& Missing & 5 & 4 \\
\hline
\end{tabular}

Table 2 indicates the summary of responses to energy efficiency in houses. Almost $70 \%$ of the respondents feel that the thermal comfort is the most important consideration in designing a house. This fact supports that the regulation of the indoor environment is essential in achieving thermal comfort. Regulation of thermal comfort can be executed in various ways; i.e. by opening and closing windows, switching on fans or air-conditioning. These steps goes from a passive energy solution of regulating the openings by closing and opening the windows; to low energy solutions of switching on the fan, to high energy means of using the air-conditioner. In addition, the research also indicates that energy efficiency and occupant behaviour to be approximately $50 \%$ of the factors that are most influential in a house design.

Table 2: Responses to Consideration of Energy Efficiency

\begin{tabular}{lllll}
\hline No & Variables & Description & Frequency & Percentage \\
\hline 1 & $\begin{array}{l}\text { The most important } \\
\text { aspect in house design }\end{array}$ & Thermal comfort & 86 & 68.8 \\
& & & \\
& & Visual Comfort & 32 & 25.6 \\
2 & Audio Comfort & 7 & 5.6 \\
& $\begin{array}{l}\text { Most influenctial factor in house } \\
\text { design }\end{array}$ & Occupant Behaviour & 32 & 25.6 \\
& & & \\
& & Energy Efficiency & 32 & 25.6 \\
& Construction Cost & 61 & 48.8 \\
\hline
\end{tabular}

Correlation analyses are performed to further test on the awareness of energy efficiency and regulation of the indoor environment. The independent variables of age and level of education are correlated to the respondents' responses on attitude and behaviour regarding house design. Table 3 shows the correlation results between the age of the respondents and environmental concerns in the home. The results shows significant correlation between respondents' age to the factors influential in house design. Another significant correlation is also seen between the age factor to the need to include energy efficient and sustainable strategies in house design. 
Table 3: Correlations Results (age of Respondents to environmental concerns in houses)

\begin{tabular}{|c|c|c|c|}
\hline \multirow[t]{24}{*}{ Spearman's rho } & Age of respondent & Correlation Coefficient & 1.000 \\
\hline & & Sig. (1-tailed) & \\
\hline & & $\mathrm{N}$ & 122 \\
\hline & 1. Consideration of energy efficiency & Correlation Coefficient & .029 \\
\hline & in designing homes & Sig. (1-tailed) & .376 \\
\hline & & $\mathrm{N}$ & 122 \\
\hline & 2. Aspect of comfort in house design & Correlation Coefficient & -.083 \\
\hline & & Sig. (1-tailed) & .183 \\
\hline & & $\mathrm{N}$ & 122 \\
\hline & 3. Factors influential in house design & Correlation Coefficient & $.170^{\circ}$ \\
\hline & & Sig. (1-tailed) & .031 \\
\hline & & $\mathrm{N}$ & $\overline{122}$ \\
\hline & 4. Aware of the importance of energy & yCorrelation Coefficient & .035 \\
\hline & efficiency in houses & Sig. (1-tailed) & .351 \\
\hline & & $\mathrm{N}$ & $\overline{121}$ \\
\hline & 5. Human behaviour influences & Correlation Coefficient & -.048 \\
\hline & energy efficiency practices & Sig. (1-tailed) & .301 \\
\hline & & $\mathrm{N}$ & 121 \\
\hline & 6. Passive architectural & Correlation Coefficient & -.021 \\
\hline & consideration in house design & Sig. (1-tailed) & .408 \\
\hline & & $\mathrm{N}$ & 121 \\
\hline & 7. Rain water harvesting,grey water & Correlation Coefficient & $-.171^{\star}$ \\
\hline & treatment,solar panel,etc. are & Sig. (1-tailed) & .031 \\
\hline & $\begin{array}{l}\text { essential energy efficiency system to } \\
\text { be included in the contemporary } \\
\text { house design. }\end{array}$ & & 119 \\
\hline & 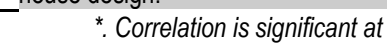 & & \\
\hline
\end{tabular}

Correlation is significant at 0.05 level (one-tailed); Spearman's rho correlation test statistics is 0.170 and -0.171 for questions No 3 and 7 describing the preferences for energy efficiency and sustainable strategies have a significant relationship to age factor. $63.1 \%$ of the respondents are below 40 years of age where the attitude and awareness towards energy efficiency are higher.

Table 4 shows that the correlation results between the level of education of the respondents and environmental concerns in the home. The results shows significant correlation between level of education to the factors influential in house design. However, there are weak correlation between the education level of respondents to other environmental concerns in choosing a home.

Correlation is significant at 0.05 level (one-tailed); Spearman's rho correlation test statistics is 0.205 for question No 3 describing that preferences for energy efficiency has a significant relationship to the level of education of the respondents. Occupant behaviour and energy efficiency is the highest score in factors influential in house design that indicated the awareness of the respondents that have tertiary education (90.8\%). 
Table 4: Correlations Results (Education Level of Respondents to environmental concers in houses)

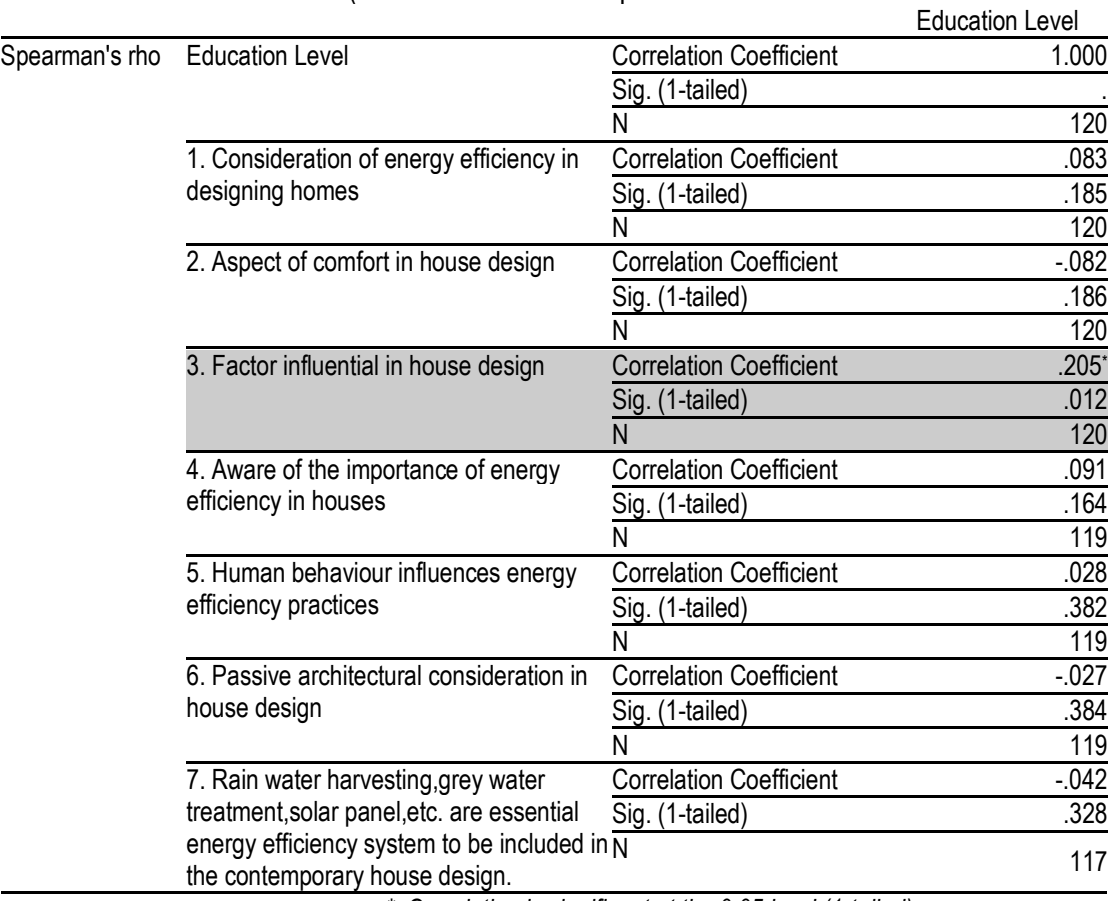

*. Correlation is significant at the 0.05 level (1-tailed).

**. Correlation is significant at the 0.01 level (1-tailed).

As discussed earlier, the respondents showed an inclination towards energy efficiency in houses. The survey on preference of comfort showed that thermal comfort is the primary concern. The cross tabulation performed on preference for comfort and the method used to regulate comfort shows correlation coefficient at 0.152 where correlation is significant at 0.05 level (one-tailed). On the other hand, the cross tabulation performed on the preference for comfort and daylighting regulation in houses showed weak correlation coefficient at 0.048 .

Table 5: Correlations Results Importance of Comfort and Method for Regulation of Thermal Comfort

\begin{tabular}{|c|c|c|c|c|}
\hline & & & $\begin{array}{l}\text { Important aspect of } \\
\text { comfort in house } \\
\text { design }\end{array}$ & $\begin{array}{l}\text { Method used to } \\
\text { regulate thermal } \\
\text { comfort }\end{array}$ \\
\hline \multirow[t]{6}{*}{ Spearman's rho } & \multirow{3}{*}{$\begin{array}{l}\text { Important aspect of } \\
\text { comfort in house design }\end{array}$} & Correlation Coefficient & 1.000 & .152 \\
\hline & & Sig. (1-tailed) & & .045 \\
\hline & & $\mathrm{N}$ & 125 & 125 \\
\hline & \multirow{3}{*}{$\begin{array}{l}\text { Method used to regulate } \\
\text { thermal comfort }\end{array}$} & Correlation Coefficient & $.152^{*}$ & 1.000 \\
\hline & & Sig. (1-tailed) & .045 & \\
\hline & & $\mathrm{N}$ & 125 & 125 \\
\hline
\end{tabular}


Abdul Majid, N.H., et.al. / Journal of ASIAN Behavioural Studies (jABs), 3(10) Sep / Oct 2018 (p.142-153)

Table 6: Correlations Results on Importance of Comfort and Method for Regulation of Daylighting

\begin{tabular}{|c|c|c|c|c|}
\hline & & & $\begin{array}{l}\text { Important aspect of } \\
\text { comfort in house } \\
\text { design }\end{array}$ & $\begin{array}{c}\text { Method you used } \\
\text { to regulate } \\
\text { daylighting }\end{array}$ \\
\hline Spearman's & Important aspect of comfort & Correlation Coefficient & 1.000 & .048 \\
\hline rho & in house design & Sig. (1-tailed) & & .299 \\
\hline & & $\mathrm{N}$ & 125 & 125 \\
\hline & Method you used to regulate & Correlation Coefficient & .048 & 1.000 \\
\hline & daylighting & Sig. (1-tailed) & .299 & \\
\hline & & $\mathrm{N}$ & 125 & 125 \\
\hline
\end{tabular}

\subsection{Conclusion}

The research proved that comfort is the main consideration in choosing and building new houses. Thermal comfort appears to be a major factor among all comfort considerations. This study have attested that thermal comfort is valued over other forms of comfort and verified that age and level of education have a significant relationship to attitude and behaviour of the inhabitants. The attitude and behaviour relationship to indoor environmental regulation supports energy efficiency practices. Opting for energy efficient concept in achieving comfort shows the respondents' awareness in regulating the indoor environment of their houses.

Since thermal comfort is the main issue in regulating the indoor environment, the research can be furthered in a scientific collection of environmental parameters that effects thermal comfort; air temperature, mean radiant temperature, humidity and air speed at the interior environment. The study should also record parsonal parameters of comfort for the occupants including factors such as clothing types and activity level of the inhabitants.

\section{References}

Abdul Majid, Noor Hanita and Hussaini, Ibrahim Udale (2011) Housing design practice and energy efficiency consideration in Nigeria. In: Third International Conference on Applied Energy, 16 - 17 May 2011, Perugia, Italy.

Abdul Majid, Noor Hanita and Hussaini, Ibrahim Udale (2011) The challenges of energy efficiency in the Nigerian households. Conference Proceedings of the 3rd International Conference on Applied Energy, Perugia, Italy, 16-18 May, pp. 1471-1482.

Abdul Majid, Noor Hanita and Hussaini, Ibrahim Udale (2012) Human behavior in household energy use and the implications of energy efficiency delivery: a case of Nigeria. In: 5 th International Conference on Sustainable Energy \& Environmental Protection (SEEP 2012), 5-8 June 2012, Dublin City Univ. Dublin, Ireland.

Abdul Rahim, Zaiton (2007) Privacy and Modification of Terrace Housing among Malay Occupants in Klang Valley, Malaysia. Unpublished PhD thesis, Universiti Putra Malaysia.

Ahmad Ezanee Hashim, Siti Aida, Samikon, Nasyari, Mat Nasir and Normazwin, Ismail (2012). Assessing Factors Influencing Performance of Malaysian Low-cost Public Housing in Sustainable Environment. Procedia - Social and Behavioral Sciences 50 (2012) 920 - 927. 
Bell, M., Lowe, R. and Roberts, P. (1996) Energy Efficiency in Housing. Avebury Ashgate Publishing Limited, Aldershot, p. 87.

Diez-Nicholas, J. (2006) Measuring and explaining environmental behaviour: the case of Spain. in Dooley, B. (Ed.), Energy and Culture: Perspectives on the Power to Work, Ashgate, Aldershot, pp. 209-229.

Hoang Manh Nguyen (2013). Cultural Behavior: Climatic adaptive approaches of traditional housing in Vietnam Northern lowland area. Procedia - Social and Behavioral Sciences 85 (2013) 368 - 382 .

Lutzenhiser, L. (1993) Social and behavioral aspects of energy use. Annual Review of Energy and Environment, Vol. 18, pp. 247-289.

Noor Hanita Abdul Majid, Prof. Abang Abdullah Abang Ali \& Dr. Abdul Razak Sapian (2004). Social and Climatic Considerations for Affordable Quality Housing. Construction Industry Research \& Development Achievement Seminar 2004 (CIRAS '04). Organised by Construction Industry Development Board Malaysia (CIDB). 22 September 2004, Palace of Golden Horses, Kuala Lumpur.

Noor Hanita Abdul Majid, Zaiton, Abdul Rahim \& Zuraini Denan. Climate Responsive strategies versus the Cultural and Religious Dimensions in the Architecture of Malay Traditional Houses, International Conference on Construction and Industry 2009 (ICCI II 2009).

Wilk, R. (1999) Towards a useful multigenic theory of consumption. Conference Proceedings of European Council for an Energy Efficient Economy ( ECEEE ) 1999 Summer Study-Panel 3.15: Human Dimensions, available at: www.eceee.org/conference-proceedings/ (accessed 16 April 2010). 